УДК 349.2

DOI https://doi.org/10.17308/vsu.proc.law.2021.1/3281

\title{
ДИСТАНЦИОННАЯ (УДАЛЕННАЯ) РАБОТА КАК ЦИФРОВОЙ СЕГМЕНТ РЫНКА ТРУДА: ПРОБЛЕМЫ И ПЕРСПЕКТИВЫ
}

\author{
Е. Р. Брюхина \\ Национальный исследовательский университет \\ "Высшая школа эконолики" \\ Поступила в редакцию 18 августа 2020 г.
}

\begin{abstract}
Аннотация: раскрывается понятие, проблель дистаниионной работы в ралках действующего трудового законодательства. Анализируется законопроект о проекте фбедерального закона № 973264-7 «О внесении изменений в Трудовой кодекс Российской Федераиии в части регулирования дистаниионной и удаленной работь», авторол обращено внимание на неточность фборлулировок, используельх в законопроекте. Расслотрень режимы рабочего времени, к которыл относится вреленная дистаниионная (удаленная) работа и колбинированная дистаниионная (удаленная) работа. Сопоставлены категории "дистаниионная работа" и "дистаниионная (удаленная) работа». Сделан вывод о необходилости закрепления понятия "удаленная работа".

Ключевые слова: дистаниионная работа, дистанционная (удаленная) работа, режим вреленной дистанционной (удаленной) работы, упрощенный порядок введения режила временной дистанционной (удаленной) работы, колбинированная дистанционная (удаленная) работа.
\end{abstract}

\begin{abstract}
: the article reveals the concept, the problem of teleworking within the framework of the current labor legislation. The draft law on the draft federal law No. 973264-7 "On amendments to the Labor Code of the Russian Federation in terms of regulating remote and remote work" is analyzed, the author draws attention to the inaccuracy of the words used in the draft law. The modes of working hours are considered, which include temporary remote (remote) work and combined remote (remote) work. The categories of teleworking and teleworking (remote) work are compared. The conclusion is made about the need to consolidate the concept of remote work.

Key words: teleworking, distant (remote) work, temporary distant (remote) work mode, a simplified procedure for introducing a temporary distant (remote) work mode, combined distant (remote) work.
\end{abstract}

Развитие информационных технологий, уход работодателей от традиционных фрорм найма сотрудников способствуют все большему распространению относительно новой фромы труда - дистанционного труда.

Действующее трудовое законодательство в вопросе регулирования дистанционного труда является весьма консервативным, не учитывающим динамику общественной жизни. Мировая ситуация с Covid-19 «оголила» болевые места и пробелы действующих нормативных положений, спровоцировала необходимость скорейшей их корректировки.

(C) Брюхина E. P., 2021 
В правоприменительной практике возникла сложная ситуация относительно применения положений главы 49.1 ТК РФ в современных реалиях в массовом порядке.

Исследователи в различных областях отмечают рост использования дистанционного труда. По данным Международной организации труда и Европейского фонда по улучшению условий жизни и труда, США являются мировым лидером по количеству удаленных сотрудников - около 37 \%, в Евросоюзе таких работников 17 \%, а в России доля дистанционных работников составляет пока лишь около $2 \%{ }^{1}$.

Почему же с учетом экономической выгоды дистанционного труда и других явных преимуществ данной формы занятости доля дистанционных работников на рынке труда в России занимает такой маленький процент? Представляется, что проблема кроется в сложностях правового регулирования данного вопроса.

До 2013 г. отношения между дистанционными работниками и их работодателями не имели правовой основы. Как отмечает К. А. Агадилова, «формально такие отношения не относились к трудовым, поэтому и работавшие дистанционно лица не являлись работниками, а значит, они были лишены установленных законом для работников прав и гарантий» ${ }^{2}$. Отсутствие правовой базы и незащищенность такой формы труда долгое время препятствовала распространению дистанционного труда на территории Российской Федерации. Следует поддержать Н. Л. Лютова, полагающего, что развитие электронных технологий подталкивает и работников, и работодателей к использованию дистанционного труда ${ }^{3}$.

В настоящее время в Трудовом кодексе РФ (далее - ТК РФ) существует целая глава, посвященная регулированию дистанционного труда. Согласно ст. 312.1 ТК РФ дистанционной работой является выполнение определенной трудовым договором трудовой функции вне места нахождения работодателя, его филиала, представительства, иного обособленного структурного подразделения (включая расположенные в другой местности), вне стационарного рабочего места, территории или объекта, прямо или косвенно находящихся под контролем работодателя, при условии использования для выполнения данной трудовой функции и для осуществления взаимодействия между работодателем и работником по вопросам, связанным с ее выполнением, информационно-телекоммуникационных сетей общего пользования, в том числе сети «Интернет» ${ }^{4}$. Поскольку взаимодействие работодателя с работником происходит в сети «Интернет», это позволяет говорить о специфичном сегменте рынка труда

${ }^{1}$ См.: Агадилова $К$. А. Дистанционные работники : особенности правового регулирования труда и специфика трудового договора // Национальное гуманитарное знание : сб. науч. трудов. Ростов н/Д., 2019. С. 18-26.

2 Там же.

${ }^{3}$ См.: Лютов Н. Л. Дистанционный труд : опыт Европейского союза и проблемы правового регулирования в России // Lex Russica. 2018. № 10 (143). C. 32.

${ }^{4}$ Трудовой кодекс Российской Федерации : федер. закон от 30 декабря 2001 г. № 197-Ф3 // Собр. законодательства Рос. Федерации. 2002. № 1. 


\section{Вестник ВГУ. Серия: Право}

и предложить сегментацию глобального рынка труда по признаку обязательного использования информационно-компьютерных технологий на всех стадиях трудовой деятельности ${ }^{5}$.

Проблемы дистанционного труда во многом связаны с тем, что типичная характеристика трудового отношения - регламентация труда как процесса, а не результата труда ${ }^{6}$ - в случае дистанционного труда подвергается существенной эрозии ${ }^{7}$ В настоящее время дистанционный труд утрачивает многие характерные признаки трудового отношения: работник не находится под непосредственным контролем работодателя, поэтому вопросы и трудовой дисциплины, и охраны труда, режима труда и отдыха, и взаимной ответственности сторон оказываются проблемными ${ }^{8}$.

Наиболее интересными с точки зрения включения определенных условий в трудовой договор с дистанционным работником являются положения относительно рабочего времени. Статьей 312.4 ТК РФ установлено, что режим рабочего времени и отдыха дистанционный работник определяет самостоятельно, если иное не установлено трудовым договором.

Если работодатель устанавливает свободный график работы, то у дистанционного работника есть право выполнять свои трудовые обязанности в удобное для него время, как полагает К. А. Агадилова, в этом случае работодателю не придется вести учет рабочего времени, отработанного дистанционным работником 9 . Это также означает, что у работника нет возможности получить дополнительную оплату за сверхурочную работу, работу в выходные и нерабочие праздничные дни, работу в ночное время. Если же работодатель устанавливает четкий режим работы дистанционному работнику, например из-за специфики выполняемой работы, - то работодатель обязан вести учет рабочего времени дистанционного ра일 ботника и доплачивать за особые условия работы (в том числе за работу в выходные и праздничные дни). Здесь же возникают практические

${ }^{5}$ См.: Панарина М. М. Актуальные вопросы дистанционной правовой работы юриста : перспективы развития правового фриланса в современных условиях //

82 Вестник Воронеж. гос. ун-та. Серия: Право. 2019. № 4. С. 126.

${ }^{6}$ См.: Куренной A. M. Труд и право : трудовое или гражданское? // Корпоративный юрист. 2005. № 1 ; Лютов H. Л. Признаки трудового правоотношения : международные нормы и российская судебная практика // Трудовое право в России и за рубежом. 2016. № 4. С. 7-11; Радевич E. P. Критерии разграничения отраслевой природы отношений в сфере труда : сравнительно-правовой анализ // Рос. ежегодник трудового права. 2013. № 8. С. 516-524.

${ }^{7}$ См., например: Васильева Ю. В., Шуралева С. В. Содержание трудового договора о дистанционной работе : теоретические аспекты // Вестник Пермского ун-та. Юридические науки. 2015. Вып. 2 (28). С. 88-97 ; Закалюжная Н. В. Дистанционная работа и схожие правоотношения // Право. Журнал Высшей школы экономики. 2015. № 2. С. 76-91.

${ }^{8}$ См., например: Агадилова К. А. Указ. соч. С. 18-26.

${ }^{9}$ См.: Там же. 
проблемы: как контролировать выполнение работы именно в отведенное время; какие условия относительно режима рабочего времени, контроля его выполнения и способов учета отработанного времени необходимо включить в трудовой договор, заключаемый с дистанционным работником $^{10}$.

Кроме того, многие авторы ${ }^{11}$ указывают на необходимость более детально урегулировать другой вопрос, связанный с рабочим временем дистанционных работников. Исследователи предлагают включать в трудовой договор право дистанционных работников не находиться круглосуточно на связи с работодателем и не отвечать на письма и звонки в определенные временные интервалы ${ }^{12}$, что нашло отражение в законопроекте о проекте федерального закона № 973264-7 «О внесении изменений в Трудовой кодекс Российской Федерации в части регулирования дистанционной и удаленной работы». Такое право представляется особенно необходимым для работников, осуществляющим трудовую функцию в дистанционном формате.

Стоит отметить иные проблемы, возникающие при правовом регулировании дистанционного труда. Требование о контроле со стороны работодателя зафиксировано в ст. 56 ТК РФ, в которой дается определение трудового договора. При дистанционной работе осуществление контроля затруднено, но возможно с помощью сети «Интернет» ${ }^{13}$. Работодателями применяются различные системы и методы контроля за выполнением работниками своих трудовых обязанностей.

Указанные обстоятельства обусловливают актуальность необходимости осмысления проблем правового регулирования дистанционного труда и предложения путей их решений.

Так, 19 марта 2020 г. «Известия» сообщили, что в Российской трехсторонней комиссии по регулированию социально-трудовых отношений, которую курирует заместитель председателя Правительства РФ Т. А. Голикова, обсудили внесение в Государственную Думу Федерального Собрания РФ законодательной инициативы о введении в ТК РФ возможности работы в режиме неполной дистанционной занятости ${ }^{14}$.

10 Там же.

${ }^{11}$ См.: Лютов Н. Л. Дистанционный труд... ; Васильева Ю. В., Шуралева C. В., Браун E. A. Правовое регулирование дистанщионной работы : проблемы теории и практики. Пермь, 2016 ; Киселева $E$. B. Развитие дистанционного труда в России : преимущества и недостатки // Известия АлтГУ. Юридические науки. 2018. № 6 (104) ; Сластя С. Д. Управление карьерой персонала, работающего на дистанционной работе // Профессиональная ориентация. 2017. № 1. С. 320-324.

${ }^{12}$ См., например: Агадилова К. А. Указ. соч.

${ }^{13}$ См.: Лузан Д. К. Особенности регулирования труда дистанционных работников // Тенденции развития науки и образования. 2019. № 49-6. С. 48-50.

${ }^{14}$ См.: Ивушкина A. Рабочее вместо : в России обсуждают введение нового вида занятости. URL: https://iz.ru/988401/anna-ivushkina/rabochee-vmesto-v-rossii-obsuzhdaiut-vvedenie-novogo-vida-zaniatosti (дата обращения: 22.03.2020). 
Необходимо отметить, что режим неполной дистанционной занятости соотносится с дистанционным трудом, как вид и род, а последний назван председателем Правительства РФ как эффективный способ организации труда в условиях пандемии коронавируса ${ }^{15}$.

В апреле 2020 г. Министерство труда и социальной защиты РФ опубликовало Рекомендации по применению гибких форм занятости в условиях предупреждения распространения новой коронавирусной инфекции на территории Российской Федерации (далее - Рекомендации), в которых определены различные формы работы на дому: удаленная, дистанционная, надомная. Обращает на себя внимание тот факт, что это три самостоятельные формы, имеющие ряд различий. В частности, удаленная работа включает элементы работы как надомной, так и дистанционной. Вводится удаленная работа на основании приказа о временном (на период мероприятий, направленных на нераспространение новой коронавирусной инфекции) переходе сотрудников на удаленную работу на дому, при этом работодатель должен для организации режима удаленной работы определить списки работников, переходящих на удаленную работу на дому и порядок организации такой работы. Следовательно, удаленная работа всегда носит временный характер, возможна только с работниками, состоящими в трудовых отношениях с работодателем, и не требует заключения дополнительного соглашения к имеющемуся трудовому договору, в отличие от дистанционной и надомной работы, предполагающей заключение трудового договора или дополнительного соглашения к трудовому договору о дистанционной (надомной) работе и носящей постоянный характер.

Законопроект федерального закона № 973264-7 «О внесении изменений в Трудовой кодекс Российской Федерации в части регулирования - дистанционной и удаленной работы» направлен на совершенствование 을 норм Трудового кодекса о дистанционной работе и урегулирование отношений временной дистанционной (удаленной) занятости.

Как отмечается в пояснительной записке, «начало пандемии Covid-19 в силу объективных обстоятельств привело к масштабному распространению режима работы вне стационарных рабочих мест, к развитию вза-

84 имодействия между сторонами трудовых отношений с использованием информационно-коммуникационных технологий. Тем самым выявились противоречия между реальными процессами в сфере труда в период пандемии и российским трудовым правом, в частности устанавливаемыми им формами занятости и рабочего времени...». Представленный законопроект разработан с целью «повышения гибкости занятости и применения информационно-коммуникационных технологий в трудовых отношениях».

15 Федеральное государственное унитарное предприятие «Информационное телеграфное агентство России». URL: https://tass.ru/ekonomika/8042921 (дата обращения: 22.03.2020). 
Проведем анализ основных его положений, который следует начать с названия законопроекта. Из смысла названия следует, что регулированию будут подвержены дистанционная и удаленная работа. Обращает на себя внимание недостаточно точная формулировка, вызывающая двоякое прочтение, связанное с использованием союза «и». Может сложиться представление, что это два отдельных, самостоятельных типа трудовых отношений, которые должны иметь самостоятельное регулирование, должны прослеживаться отличительные черты, основания возникновения, изменения и прекращения этих отношений. Другой вариант прочтения трактуется сквозь призму однородных членов предложения, в котором союз «и» связывает два одинаковых по значению слова, следовательно, категория “дистанционная и удаленная работа» трактуется как единое понятие, тем самым дистанционная работа и удаленная работа это одинаковые категории. По тексту законопроекта термин «удаленная работа" используется как пояснение понятия дистанционная работа путем использования употребления термина в скобках. Думается, что в таком случае соединительный союз «и» следует заменить и привести текст и название к единообразию, чтобы исключить различные толкования.

Далее еще более интересно: предлагается наименование главы 49.1 «Особенности регулирования труда дистанционных работников» изложить в следующей редакции: «Особенности регулирования дистанционной и временной удаленной работы», что вступает вразрез с названием законопроекта. Появляется новая категория «временная дистанционная (удаленная) работа", являющаяся режимом работы, предусматривающим временное выполнение трудовой функции работника, работающего на основании трудового договора, вне стационарного рабочего места, находящегося под контролем работодателя. Вероятнее всего, законодатель такой формулировкой указывает на то, что удаленная работа может носить исключительно временный характер, временность определяется каким-либо основанием или обстоятельством. В связи с этим возникает вопрос, может ли удаленная работа носить постоянный характер? Думается, что может, связано это еще с одной новой категорией - «комбинированная дистанционная (удаленная) работа», определяемая законодателем как режим работы, включающий работу на стационарном рабочем месте и дистанционную (удаленную) работу, что является нововведением, ибо действующее законодательство не предусматривает сочетание дистанционной работы с работой в месте расположения работодателя. Предусматривая возможность установления комбинированного режима дистанционной (удаленной) работы, не определено, на какой период он может быть установлен. Из смысла законопроекта следует, что комбинированная дистанционная (удаленная) работа может быть установлена как постоянно, так и временно.

Из определения, изложенного в действующей редакции ТК РФ, следует, во-первых, что дистанционная работа выполняется вне места на- 


\section{Вестник ВГУ. Серия: Право}

хождения работодателя, его обособленного структурного подразделения, вне стационарного рабочего места, территории или объекта, прямо или косвенно подконтрольных работодателю. Во-вторых, для выполнения трудовой фонкции и для взаимодействия с работодателем дистанционный работник должен использовать информационно-коммуникационные сети общего пользования, в том числе сети «Интернет» ${ }^{16}$. Тем самым определено два основных признака дистанционной работы. Сопоставляя понятия «дистанционная работа» в действующей редакции ТК РФ и понятие «дистанционная (удаленная) работа», предложенное в законопроекте, усматривается их идентичность, что означает наличие одинаковых признаков у дистанционной и удаленной работы.

Таким образом, законодатель определил такой тип трудовых отношений, как дистанционная (удаленная) работа. Данные понятия являются идентичными и предполагают возможность установления двух режимов рабочего времени, к которым относится временная дистанционная (удаленная) работа и комбинированная дистанционная (удаленная) работа.

Думается, необходимо на законодательном уровне разграничить понятия дистанционной работы и удаленной работы. При дистанционной работе работодатель может никогда не увидеть своего работника, трудовой договор в этом случае необходимо заключать дистанционно, с использованием всех информационно-коммуникационных средств, аналогично при взаимодействии (в процессе трудовых отношений) дистанционный работник и работодатель должны использовать информационно-коммуникационные сети общего пользования, в том числе сеть «Интернет». При дистанционной работе может устанавливаться гибкий режим работы в отличие от дистанционной (удаленной). При дистанци-

- онной (удаленной) работе заключается трудовой договор с установлением режима удаленной работы либо временного, либо комбинированного характера. В этом случае работодатель и работник хотя бы один раз (при заключении трудового договора) взаимодействуют без использования информационно-коммуникационных сетей общего пользования, в том числе сети «Интернет».

Возвратимся к законопроекту. Законодателю необходимо определить и ввести четкие отличия в рассматриваемых формах занятости дистанционной и дистанционной (удаленной) работы, в противном случае возникнут сложности в правоприменительной практике процедурного характера.

Из смысла ст. 312.1-1 «Общие положения о дистанционных работниках» следует, что дистанционными работниками считаются лица, заключившие трудовой договор о дистанционной работе. Таким образом, при введении локальным актом режима временной дистанционной (удален-

${ }^{16}$ См.: Васильева Ю. В., Шуралева С. В. Дистанционная работа : новые возможности для российского бизнеса // Journal of Economy and entrepreneurship. 2015. Vol. 9, № 9-2. P. 962. 
ной) работы в упрощенном порядке работник меняет свой статус на дистанционного работника.

Относительно упрощенного порядка введения режима временной дистанционной (удаленной) работы, который в соответствии со ст. 312.6 «Временная дистанционная (удаленная) работа» законопроекта должен предусматривать издание локального нормативного акта с установлением списков работников, переводимых с их согласия на временную дистанционную (удаленную) работу, а также порядок организации режима временной дистанционной (удаленной) работы, в том числе: срок, на который работник переводится на временную дистанционную (удаленную) работу; график работы на стационарном рабочем месте и за его пределами, возможность его последующей корректировки (при необходимости); режим рабочего времени, в том числе время, в течение которого работник должен находиться в режиме доступности для связи с работодателем в пределах рабочего времени, установленного правилами внутреннего трудового распорядка (если указанный режим отличается от установленного правилами внутреннего трудового распорядка); другие вопросы.

С локальным нормативным актом о введении режима временной дистанционной (удаленной) работы в упрощенном порядке, а также вносимыми в него изменениями необходимо ознакомить работника в соответствии с установленным способом взаимодействия. Возникает несколько вопросов, относительно применения этих положений. Во-первых, в какой период времени работодатель должен разработать и принять этот локальный акт в организации. Если проанализировать сложившуюся ситуацию весной 2020 г., связанную с Covid-19, то у работодателя не будет необходимого времени для разработки, соблюдения процедур согласования с представительным органом организации (в случае если он имеется), а также ознакомления работников, тем самым законодатель создает ситуацию, при которой возникнут массовые нарушения норм законодательства. Либо второй вариант: работодатели вынуждены будут разрабатывать и принимать, на всякий случай, указанный локальный акт.

Законопроект предусматривает согласие работника на введение режима временной дистанционной (удаленной) работы в упрощенном порядке, но не предусматривает процедуры недачи этого согласия работником. Какие действия должен совершить работодатель: ввести простой для этого работника, прекратить с ним трудовые отношения, будет ли это время считаться нерабочими днями, подлежащими оплате? Если работник отказывается от работы на условиях режима временной дистанционной (удаленной) работы, может ли работодатель заключить трудовой договор с иным работником на этот период времени? Предположим, чтобы не нарушать права работников и принцип свободы труда, следует предусмотреть обязанность работодателя не прекращать с таким работником трудовых отношений и производить оплату этого времени. Возникает вопрос: не приведет ли это к массовому злоупотреблению своим правом со 


\section{Вестник ВГУ. Серия: Право}

стороны работников? В связи с этим полагаем, что упрощенный порядок введения режима временной дистанционной (удаленной) работы целесообразнее вводить приказом организации с установлением списков работников, переводимых на временную дистанционную (удаленную) работу; срока, на который работник переводится на временную дистанционную (удаленную) работу; графика работы на стационарном рабочем месте и за его пределами, возможность его последующей корректировки (при необходимости); режима рабочего времени, в том числе время, в течение которого работник должен находиться в режиме доступности для связи с работодателем в пределах рабочего времени, установленного правилами внутреннего трудового распорядка (если указанный режим отличается от установленного правилами внутреннего трудового распорядка). При введении упрощенного порядка введения режима временной дистанционной (удаленной) работы согласие работника не должно требоваться, ибо этот порядок вводится при наличии определенных оснований и на определенный срок.

Действующее трудовое законодательство, а также законопроект о проекте фредерального закона № 973264-7 «О внесении изменений в Трудовой кодекс Российской Федерации в части регулирования дистанционной и удаленной работы» не предусматривают ограничения по возрасту для дистанционных работников, следовательно, на дистанционную работу может быть принят несовершеннолетний. Так, Т. А. Избиенова, А. О. Чупракова, а также Е. В. Охотникова ${ }^{17}$ отмечают что глава 49.1 ТК РФ, устанавливая правовые основы труда дистанционных работников, не определяет особенностей регулирования труда с участием несовершеннолетних. Каких-либо ограничений по возрасту принимаемых дистанционных работников законодательство не содержит. Труд несовершенно-

- летних работников является особым объектом правового регулирования,

인 и с учетом современных реалий социально-трудовые права таких работников должны быть надежно защищены ${ }^{18}$. Думается, что возрастные ограничения, относительно использования труда несовершеннолетних в режиме дистанционной (удаленной) временной либо комбинированной работы, должны быть регламентированы с учетом особенностей этой воз-

88 растной категории работников.

Приведенный анализ некоторых положений законопроекта о проекте фредерального закона № 973264-7 «О внесении изменений в Трудовой кодекс Российской Федерации в части регулирования дистанционной и удаленной работы», а также доктрины позволяет сделать выводы, что дистанционный труд в Российской Федерации получает все большее рас-

${ }^{17}$ См.: Oхотникова E. B. Проблемы правового регулирования труда дистанционных работников в России // Ученые записки Тамбовского отделения РОСМУ. 2019. № 14. C. 128-134.

${ }^{18}$ См.: Избиенова Т. А., Чупракова А. О. Дистанционные трудовые отношения как форма нетипичной трудовой занятости // Марийский юрид. вестник. 2017. № 1 (20). C. 101-103. 
пространение и развитие. Такое развитие требует улучшения его механизма правового регулирования. При дальнейшем совершенствовании необходимо учитывать опыт наднационального регулирования дистанционного труда, а также уделить внимание устранению правовых коллизий между отдельными положениями ТК РФ, регулирующими общие положения заключения трудового договора и особенности дистанционного труда.

Национальный исследовательский университет "Высшая школа эконолики»

Брюхина E. Р., кандидат юридических наук, доцент кафбедры гражданского и предпринилательского права

E-mail:erbruhina@hse.ru
National Research University "Higher School of Economics"

Bryukhina E. R., Candidate of Legal Sciences, Associate Professor of the Civil and Business Law Department

E-mail:erbruhina@hse.ru 